\title{
Justicia constitucional: casos de protección a la libertad y seguridad personal en Colombia ${ }^{\star}$
}

\author{
Constitutionallustice: Cases of Protection of Freedom \\ and Personal Security in Colombia \\ Justiça constitucional: casos de proteção judicial à liberdade \\ e segurança pessoal na Colômbia
}

\author{
VIRIDIANA MOLINARES HASSAN** \\ Universidad del Norte
}

FECHA DE RECEPCIÓN: 4 DE DICIEMBRE DE 2013 • FECHA DE ACEPTACIÓN: 24 DE ABRIL DE 2014

Doi: dx.doi.org/10.12804/esj16.02.2014.03

Para citar este artículo: Molinares H., V. (2014). Justicia constitucional: casos de protección a la libertad y seguridad personal en Colombia. Estudios Socio-Jurídicos, 16(2), 89-126. Doi: dx.doi.org/10.12804/esj16.02.2014.03

\section{RESUMEN}

En este artículo, presentamos los resultados de una investigación sobre la protección judicial a la libertad y seguridad personal otorgada por parte de la Corte Constitucional (cC) colombiana, con un análisis comparativo entre el período 1992-2001, al que hemos nombrado período de gobiernos posconstitucionales, que coincide con la expedición de la Constitución de 1991 (CP) y la creación de la jurisdicción constitucional; y el período 2002 a 2010, durante el cual se ejecutó la Política de Seguridad Democrática (PSD) propuesta como política de gobierno por el expresidente Álvaro Uribe Vélez, cuyo objetivo fue alcanzar la paz a través de la declaratoria de guerra al grupo guerrillero Fuerzas Armadas Revolucionarias de

* Este artículo hace parte de la investigación doctoral desarrollada por la autora en la Universidad Autónoma de Barcelona: Libertad y seguridad: papel de la Corte Constitucional colombiana en la protección de derechos fundamentales, dirigida por el doctor Joan Lluís Pérez Francesch, en el programa de doctorado en Derecho Público y Filosofía Jurídico-Política (2009-2012). Algunos de sus apartes fueron presentados en el evento internacional Seminario El Derecho y la Democracia en la Era de la Globalización, discusión de la obra Principia iuris de Luigi Ferrajoli, realizado el 29 y 30 de abril en la Universidad del Norte (Barranquilla, Colombia).

** Doctora en Derecho Público y Filosofía Jurídico-Política de la Universidad Autónoma de Barcelona (España); magíster en Literatura Comparada y Estudios Culturales de la Universidad Autónoma de Barcelona (España); magíster en Desarrollo Social de la Universidad del Norte (Barranquilla, Colombia); diplomada en Derechos Humanos y Derecho Internacional Humanitario de la American University (Washington D.C., EE. UU.). Directora de la Maestría y de la Especialización en Derecho Público de la Universidad del Norte; profesora investigadora, miembro de los grupos de investigación en Derecho y Ciencia Política, y Sociología Jurídica de la Universidad del Norte. Correo electrónico: vmolinar@uninorte.edu.co 
Colombia (FARC). Nuestro interés es demostrar que la protección a la libertad y seguridad personal, como fundamento del Estado constitucional (EC) encuentra en la CC su mayor garante, incluso frente a tribunales de cierre de otras jurisdicciones que aún están arraigados al fallido paradigma iuspositivista, desconociendo los postulados del neoconstitucionalismo suficientemente desarrollados por la CC, desde un proceso de interpretación creativa y decisoria. Esto unido a la importancia que reviste para las ramas del poder y los asociados el conocimiento del alcance de la libertad y seguridad personal que ha desarrollado la cC en el difícil contexto de guerra irregular que se vive en Colombia; y a la vez se constituye, para el constitucionalismo universal, en un referente sobre el desarrollo del garantismo judicial en el contexto del constitucionalismo actual.

Palabras clave: libertad y seguridad, justicia constitucional, garantismo, Estado constitucional.

\begin{abstract}
In this paper we present the results of an investigation about judicial protection of freedom and personal security granted by the Constitutional Court (CC) of Colombia, with a comparative analysis between the period 1992-2001, to which governments have appointed period of postconstitucionales, which coincides with the issuance of the 1991 Constitution, and the creation of constitutional jurisdiction, and the period 2002-2010, during which it ran the Democratic Security Policy (DSP) as a government policy proposal by former president Álvaro Uribe, whose aim was to achieve peace through the declaration of war to the guerrilla group Revolutionary Armed Forces of Colombia (FARC). Our interest is to show that the protection of freedom and personal security as the basis of the Constitutional (EC) finds in the CC his greatest guarantor, even against closing courts in other jurisdictions that are still rooted in the failed legal positivist paradigm, ignoring the postulates of neoconstitutionalism DC sufficiently developed from a process of creative interpretation and decision-making. This coupled with the importance for the branches of power and knowledge associated scope of freedom and personal security developed by the CC in the difficult context of irregular warfare that exists in Colombia, yet it is, for universal constitutionalism, an example of the development of legal guarantor in the context of current constitutionalism.
\end{abstract}

Key words: freedom and security, justice constitutional guarantees, constitutional state.

\title{
RESUMO
}

Neste artigo apresentamos os resultados de uma pesquisa sobre a proteção judicial à liberdade e segurança pessoal outorgada por parte da Corte Constitucional (CC) colombiana, com uma análise comparativa entre o período 1992-2001, ao que temos nomeado período de governos pós-constitucionais, que coincide com a expedição da Constituição de 1991 (CP), e a criação da jurisdição constitucional; e o período 2002 a 2010, durante o qual se executou a Política de Segurança Democrática (PSD) proposta como política de governo pelo ex- presidente Álvaro Uribe Vélez, cujo objetivo foi alcançar a paz através da declaratória de guerra ao grupo guerrilheiro Forças Armadas Revolucionárias da Colômbia (FARC). Nosso interesse é demonstrar que a proteção à liberdade e segurança pessoal, como fundamento do Estado Constitucional (EC) encontra na CC seu maior garante, inclusive frente a Tribunais de fechamento de outras jurisdições que ainda encontram-se arraigados ao frustrado paradigma juspositivista, desconhecendo os postulados do neoconstitucionalismo suficientemente desenvolvidos pela CC, desde um processo de interpretação criativa e decisória. Isto unido à importância que reveste para as ramas do poder e os associados ao conhecimento do alcance da liberdade e segurança pessoal que tem desenvolvido a CC no difícil contexto 
de guerra irregular que se vive na Colômbia; e à vez constitui-se, para o constitucionalismo universal, em um referente sobre o desenvolvimento do garantismo judicial no contexto do constitucionalismo atual.

Palavras-chave: liberdade e segurança, justiça constitucional, garantismo, Estado Constitucional.

\section{Introducción}

Después de la expedición de las constituciones contemporáneas de la segunda posguerra, ${ }^{1}$ el derecho, con su nuevo carácter constitucional y garantista, enfrenta complejos problemas planteados, entre otros aspectos, en el intento de aprehensión del alcance de las nuevas constituciones, ya que estas superan el viejo modelo iuspositivista, y, por el contrario, se despliegan en principios y valores. ${ }^{2}$ Establecer y proteger su contenido requiere ahora una fuerte labor de interpretación que exige protagonismo judicial, ${ }^{3}$ así como genera interrogantes en torno al desconocimiento, por parte de los administradores de justicia e incluso de los asociados, de los precedentes desarrollados por los tribunales constitucionales que se han convertido en sus guardianes.

1 Nos referimos a los nuevos documentos constitucionales de posguerra que dan lugar al nacimiento del constitucionalismo actual, como la Carta de las Naciones Unidas de 1945, la Declaración Universal de los Derechos Humanos de 1948, la Constitución italiana de 1948 y la Ley Fundamental de la República Federal Alemana de 1949, y a las constituciones europeas que las precedieron, así como a las constituciones latinoamericanas expedidas a partir de la década de los noventa.

2 Como lo explica Luis Prieto Sanchís en su intento por establecer la relación entre el constitucionalismo y el paradigma iuspositivista: “... sería erróneo pensar que simplemente la Constitución ha sustituido a la ley, de manera que el juez tan solo haya debido cambiar su parámetro de enjuiciamiento; pues sucede que la estructura de la norma constitucional es distinta a la de la norma legal o, al menos así parece ocurrir con los llamados principios constitucionales, que son, según opinión difundida, las más genuinas normas constitucionales" (Prieto Sanchís, 1999, p. 19).

3 Sobre el tema, Miguel Carbonell, en el prólogo a Teoría e ideología de la interpretación constitucional de Riccardo Guastini, explica que jurídicamente son muy conocidos los problemas de la interpretación constitucional, derivados en parte de las dificultades inherentes a todo proceso hermenéutico, pero también de las características del objeto por interpretar. Sigue la famosa frase del gran juez John Marshall, que, en la sentencia McCulloch vs. Maryland de 1819, afirmó: "No olvidemos que es una Constitución lo que estamos interpretando", indicando además que esta frase fue calificada por el también juez de la Suprema Corte estadounidense Felix Frankfurter como "la más importante jamás pronunciada acerca de la interpretación constitucional". De otra parte, señala Carbonell sobre la Constitución: "La textura abierta está presente en todo texto normativo, lo está todavía más tratándose de normas tan generales y ambiguas como lo son las constituciones. No podría ser de otra forma, en la medida en las que las cartas constitucionales son el compendio de complejos compromisos políticos" (Guastini, 2010, p. 73). 
En el caso colombiano, la Corte Constitucional ha enfrentado estos problemas estableciendo que sus fallos sobre revisión de constitucionalidad (SC) son obligatorios y vinculantes para todos los operadores judiciales; no así los fallos expedidos en procesos de revisión de tutelas, que, por carecer de una disposición constitucional expresa, no son obligatorios, pero sí vinculantes. ${ }^{4}$

La Corte ha explicado que el carácter vinculante de sus fallos de tutela (ST) responde a un objetivo específico: la salvaguarda del principio de igualdad ante el trato recibido de la administración de justicia; no obstante, en la práctica sí tienen un carácter obligatorio, puesto que los operadores de justicia solo pueden desconocerlos si presentan argumentos que desvirtúen la interpretación de la Corte, lo cual es poco probable; además de sumársele a esta situación que la inaplicación de un precedente de tutela, por el simple desconocimiento, conlleva a la materialización de lo que se denomina vía de hecho, cuya consecuencia es la nulidad de la sentencia, sin perjuicio de la responsabilidad disciplinaria y penal que se le puede imputar al administrador de justicia. ${ }^{5}$

4 La Corte Constitucional colombiana se ha pronunciado sobre el alcance de sus precedentes de tutela en varias sentencias, entre las cuales encontramos la ST-292 de 2006 con ponencia del magistrado Manuel José Cepeda Espinosa, desde la cual se puede concluir que "respecto a la fuerza vinculante del precedente constitucional no existen dudas sobre las facultades de la Corte, pero con los precedentes en materia de tutela nos ubicamos en un escenario completamente diferente, debido a que no es totalmente cierto que no tengan carácter obligatorio, ya que su alcance de vinculante sólo puede ser desvirtuado por circunstancias que, de presentarse, deben ser evaluadas por la Corte y no por los operadores; lo cual complejiza la labor del juez con relación a la necesidad de desarrollar técnicas para ubicar ratios decidendi, so pena de incurrir en vía de hecho, y a su actualización constante en el conocimiento de las interpretaciones del texto constitucional y del alcance de los derechos fundamentales por parte de la Corte, lo cual daría lugar a que la constitucionalización del derecho se expanda a la jurisprudencia constitucional, como indiscutible fuente formal, de forma explícita en materia de constitucionalidad y de manera implícita en tutela" (Molinares, 2006).

5 No obstante lo delicado de la cuestión, el ordenamiento jurídico no consagra una metodología específica que derive en procesos de determinación de pasos para señalar de forma expresa la ratio decidendi de las sentencias, que aplicadas sucesivamente han de constituirse en los precedentes obligatorios y vinculantes que se les exige aplicar a todos los jueces.. Atendiendo a esta situación, la Corte Constitucional colombiana ha intentado disminuir el delgado espacio entre el formalismo y el antiformalismo judicial desarrollando, desde la interpretación constitucional, una metodología para el estudio de los casos sometidos a su consideración a la que ha denominado juicio integrado de constitucionalidad. Para la Corte, este "[...] Implica entonces que la Corte comienza por determinar, según la naturaleza del caso, el nivel o grado de intensidad con [ell cual se va a realizar el estudio de la igualdad, para luego adelantar los pasos subsiguientes con distintos niveles de severidad [...]. Así, la fase de 'adecuación' tendrá un análisis flexible cuando se determine la aplicación del juicio dúctil, o más exigente cuando corresponda el escrutinio estricto. Igualmente sucederá con los pasos de 'indispensabilidad' y 'proporcionalidad en estricto sentido" (ST-352/97, M. P. Eduardo Cifuentes). 
En este contexto, la labor de revisión de fallos de tutela por parte de la Corte se realiza para el establecimiento de los precedentes que deben orientar a todos los operadores judiciales y además, atendiendo al carácter personalista del Estado colombiano, ${ }^{6}$ al derecho a la paz; ${ }^{7}$ esto último en razón a que las particulares condiciones de guerra irregular en Colombia generan una constante tensión entre las políticas públicas de confrontación con los grupos armados ilegales y el respeto a la libertad y seguridad personal de los asociados que constitucionalmente cuentan con un derecho a la paz consagrado con un carácter individual. La libertad y seguridad personal, como demostraremos más adelante, solo cuenta en Colombia con la garantía de protección que la Corte Constitucional le ha venido otorgando en sede de revisión de tutelas.

Lo anterior genera la obligación por parte de los otros poderes, de los jueces de igual e inferior jerarquía, y de los asociados de revisar los precedentes sobre protección a la libertad y seguridad personal desarrollados por la CC, que a continuación describimos, contribuyendo esta investigación a ubicar, analizar y visibilizar el contenido mismo de la Carta, en el marco del fuerte Estado constitucional que intenta consolidarse desde la interpretación auténtica que efectúa la jurisdicción constitucional.

6 Para entender el alcance del carácter personalista del Estado colombiano, recurrimos a la explicación que de este realizó el exmagistrado de la Corte Carlos Gaviria. Analiza Gaviria los principios constitucionales de dignidad ( $\mathrm{CP}$, art. $1^{\circ}$ ), igualdad ( $\mathrm{CP}$, art. 13) y libre desarrollo de la personalidad (CP, art. 16), para llegar a la conclusión de que Colombia no es un Estado paternalista, fundado en la represión, sino, por el contrario, un Estado personalista, en el cual cada sujeto representa un fin en sí mismo y como tal toda la actuación del Estado debe estar fundada en el respeto incondicional a su desarrollo de acuerdo con las decisiones que este considere apropiadas para dirigir su propia vida (Gaviria, s.f.).

7 En la Constitución colombiana se considera el derecho a la paz como un derecho individual consagrado en el artículo 22 de la Constitución Política. Sobre el derecho a la paz en Colombia, hacemos alusión a la obra de Diego Uribe Vargas, en la que afirma que constituye la condición esencial para el ejercicio del resto de derechos (Uribe Vargas, 1996). En el mismo sentido, explica Ferrajoli que uno de los criterios de distinción de los derechos humanos es "el de nexo entre derechos humanos y paz, confirma, además, que deben estar garantizados como derechos fundamentales todos los derechos vitales cuya garantía es condición necesaria para la paz: [...]" (Ferrajoli, 2008, p. 111). Las reflexiones de Uribe Vargas y Ferrajoli pueden aplicarse entonces a la realidad colombiana, por cuanto solo desde la protección judicial a las libertades es posible garantizar el derecho a la paz, como trataremos de poner en evidencia desde el análisis jurisprudencial que presentamos. 


\section{Metodología}

Exponemos en esta parte una descripción del análisis sobre sentencias de revisión de tutelas expedidas por la $\mathrm{CC}^{8}{ }^{8}$ con respecto a las libertades durante el período de ejecución de la PSD. ${ }^{9}$

Para la revisión, establecimos como categorías de análisis: la tipología de sujetos que solicitaron la protección, las particularidades de las órdenes expedidas para lograr la protección y el enfrentamiento entre la Corte Suprema de Justicia (CSJ) y la CC, reflejado en el proceso de revisión y la revocatoria por parte de esta última de las decisiones adoptadas por la CSJ, para, por el contrario, otorgar la protección que en sede de la jurisdicción ordinaria había sido negada.

La referencia a este período obedece a que representa ocho años de un gobierno excepcional, en el marco de los gobiernos posconstitucionales; esta excepcionalidad se deriva de la búsqueda de la paz a través de la guerra, en cuya dinámica necesariamente se presenta una tensión entre las estrategias de confrontación armada y la restricción a las libertades.

Para llevar a cabo el estudio cuantitativo y cualitativo de la protección que se brindó a las libertades, acudimos a la clasificación que establece Luigi Ferrajoli sobre libertades inmunidades y libertades facultades. Las primeras, explica este autor, hacen relación a las libertades que facultan actuaciones subjetivas de las personas y frente a las cuales el poder del Estado debe replegarse; mientras que las libertades facultades se refieren a las libertades para, es decir, facultan, en el marco de una estructura normativa, la realización de conductas que vinculan al sujeto, a la sociedad y al Estado.

8 Para realizar el análisis de las sentencias de la CC, recurrimos a la determinación de una muestra representativa, conforme con los datos arrojados por el programa Decision Analyst Stats TM 2.0, disponible para descarga en http://www.decisionanalyst.com/Index.dai

9 La PSD tuvo como antecedente la etapa conocida como 'recrudecimiento' de la guerra derivada de acciones terroristas de las FARC, acaecida a finales de la década de los noventa. Como respuesta a estas confrontaciones, el presidente Álvaro Uribe Vélez, al posesionarse en su cargo, en 2002, propuso como política de su gobierno la guerra a las FARC. Las acciones estratégicas de esta política consistieron en fortalecer a las Fuerzas Militares incrementando las partidas presupuestales para su modernización; además, incluyó una red de informantes y soldados campesinos, involucrando civiles en el conflicto. Los recursos para ejecutar la PSD provinieron de los Estados Unidos a través del acuerdo denominado Plan Colombia, que diseñó el gobierno inmediatamente anterior del presidente Andrés Pastrana; después continuaron con el Plan Patriota de 2004, que, finalmente, tomó el nombre de Plan Consolidación. También se pudo ejecutar con los recursos derivados de una reforma tributaria (Ávila Martínez, 2008). 
De acuerdo con Ferrajoli, entre las libertades inmunidades, se encuentran: la libertad personal, las distintas formas de habeas corpus, el derecho a la privacidad, la inviolabilidad de domicilio y de las comunicaciones privadas: en general todos los derechos de libertad consistentes únicamente en la inmunidad de interferencias o de violaciones de terceros. Entre las libertades facultades, están las facultades agendi, como la libertad de reunión, de asociación, de manifestación del pensamiento, de prensa (Ferrajoli, 2008, p. 111).

Atendiendo esta clasificación, en esta investigación, organizamos las sentencias sobre libertades expedidas por la CC en los siguientes dos grupos: libertades inmunidades: entre las que incluimos la libertad personal, de aprendizaje, cátedra o enseñanza, circulación o locomoción, conciencia, culto, elección o escogencia, expresión, información, laboral, pensamiento u opinión, prensa, profesión u oficio y sexual. Libertades facultades: entre las que incluimos la contractual, afiliación, asociación, competencia, configuración, empresa, inversión, negociación, reunión, tarifas, económicas, legislativas, probatoria, sindical.

Con el objetivo de tener referencias sobre la mutación en torno a la protección judicial a las libertades, los resultados de la investigación se presentan bajo un parámetro comparativo entre el período que inicia con la expedición de la Constitución de 1991, y junto a ello con el inicio de la jurisdicción constitucional, en 1992, hasta el año 2001, que hemos llamado período de gobiernos posconstitucionales, y el período 2002-2010, que identificaremos como de PSD.

Basándonos en el análisis estadístico, haremos especial énfasis en la protección al derecho a la libertad y seguridad personal, que se ubica en el ámbito de libertades inmunidades porque este fue el derecho sobre el cual la CC expidió el mayor número de sentencias tanto en el período de gobiernos posconstitucionales como en el período de PSD.

En el período 1992-2001, por ejemplo, se expidieron un total de 446 SC y ST, relativas a las libertades; ${ }^{10}$ dentro de las cuales, el $24 \%$ correspondió a pronunciamientos sobre la libertad personal, seguida de un $20 \%$ relativo

10 Aplicando el programa Decision Analyst Stats TM 2.0. Del total de 446 sentencias en materia de libertades expedidas durante 1992-2001, el programa arrojó como muestra representativa 51 sentencias sobre libertades facultades y 53 en el campo de libertades inmunidades, con un margen de error del 10\%, una muestra estimada del 50\% y un nivel de confianza del $90 \%$. 
a la libertad de configuración legislativa; en tercer lugar, encontramos las libertades sindicales y de circulación o locomoción con un 8\%.

Lo anterior nos lleva a confirmar que, no obstante la recién expedida Constitución para la Paz, las solicitudes de protección, vía judicial, del derecho a la libertad personal no disminuyeron, presumiblemente a causa del afianzamiento del movimiento paramilitar que en la década de los noventa logró en el país su mayor expansión con la unificación de todos los grupos de autodefensas, en abril de 1997, en las Autodefensas Unidas de Colombia (AUC); o como continuación de la violencia política que, a esta fecha, da cuenta del incremento de actores asociados a la guerra irregular en el país.

Siguiendo en el mismo orden, y bajo la misma lógica de guerra irregular, encontramos que en el PSD aumentaron el número de sentencias expedidas por la CC relativas a las libertades, aunque continuó siendo la libertad personal el derecho sobre el cual recayó el mayor número de pronunciamientos.

De un total de 471 sentencias ST y SC, que fueron analizadas en su integridad, la libertad personal representó el 29,36\% de los pronunciamientos, es decir, se incrementó en un 5,36\% con relación al período anterior, si bien este representaba nueve años (1992-2001), mientras el PSD comprendió ocho (2002-2010).

En segundo lugar, y al igual que en el período de gobiernos posconstitucionales, pero con una disminución considerable, encontramos que las sentencias recayeron sobre la libertad de configuración legislativa en razón de un $12,55 \%$, es decir, se presentó una reducción del 5,45\%; de igual forma, disminuyó el porcentaje relativo a las libertades sindical, de expresión, circulación, de competencia, contractual, de conciencia, de cátedra o enseñanza, de prensa, laboral, contractual, de empresa; mientras que aumentaron frente a las libertades de asociación, económica, profesión u oficio, culto, de elección o escogencia, de información.

Ello nos plantea como escenario que en 18 años de jurisdicción constitucional en Colombia, el mayor número de órdenes de protección recayeron sobre la libertad personal, con un incremento considerable en el período de PSD. Entonces, se puede afirmar que la población recurre a la CC para su protección, ante la ineficacia de la rama ejecutiva para hacerlo, e, incluso, ante la irrupción ilegal de las autoridades del Estado, que, desconociendo su deber constitucional de protección a todas las personas en su vida, honra y bienes $\left(\mathrm{CP}, \operatorname{art} .2^{\circ}\right)$, generan un número importante de estas violaciones, 
como podemos constatar en el análisis de cada uno de los casos que presentamos a continuación.

Este análisis se realiza para poner en evidencia que la CC, bajo un paradigma de interpretación evolutiva y creativa de la $\mathrm{CP}_{1}{ }_{1}^{11}$ así como expide órdenes de protección inmediatas, razonables y proporcionales que afirman los postulados del garantismo judicial, también apoya la construcción del EC en medio de la guerra irregular, mediante la revisión de constitucionalidad de las leyes.

Junto a lo anterior, confirmamos que la CC en su proceso de revisión de sentencias de tutela, y teniendo como objetivo la unificación de la interpretación de la $\mathrm{CP}$ y la construcción de lo que deberían ser inquebrantables precedentes constitucionales, revoca, en un importante porcentaje, fallos de instancia anteriores, incluso de los tribunales de cierre de las otras jurisdicciones, de tradición iuspositivista, para conceder la protección solicitada y establecer que, en Colombia, la supremacía constitucional en cuanto paradigma del EC tiene en el juez constitucional el mayor protagonista.

Teniendo en cuenta que, en Colombia, la libertad personal es la libertad frente a la cual la CC expidió el mayor número de sentencias, procedemos a analizar los precedentes constitucionales que esta corporación ha desarrollado, en la determinación del alcance de esta libertad en el EC.

\section{E1 juez y la balanza: protección judicial a la libertad y seguridad personal}

El Estado colombiano es un Estado paradigmático. Se desarrolla entre un marco constitucional aspiracional ${ }^{12}$ que cobija todos los derechos humanos,

11 Nos referimos aquí a la distinción que realiza Guastini sobre los dos aspectos enunciados. Guastini explica que la interpretación creativa, que consiste en atribuir a un texto un significado nuevo, no comprendido entre los identificables por medio de la interpretación cognitiva -y/o en recabar del texto de las normas llamadas implícitas-, a través de medios pseudológicos (o sea, concluyentes: por ejemplo, mediante el argumento analítico); y con relación a la doctrina dinámica, sostiene que se inspira en el valor de la adaptación continua del derecho a las exigencias de la vida social (política, económica, etc.). Por ello, esta doctrina sugiere a los intérpretes no practicar una interpretación fija, sino, por el contrario, cambiar el significado del texto a la luz de las circunstancias ( $y$, bien entendido, a la luz de sus sentimientos de justicia). En otras palabras, la doctrina favorece una interpretación 'evolutiva', tiende a remediar el envejecimiento de la Constitución y la falta de revisiones constitucionales (Guastini, 2010, p. 97).

12 Para entender el alcance del constitucionalismo aspiracional al que nos referimos, puede 
consagrando incluso una cláusula de ampliación a estos, ${ }^{13}$ y una guerra irregular con violencias mutantes, que da lugar a la ya habitual violación a las libertades básicas de la población.

Entre el universo de esas violaciones, resalta la violación al derecho a la libertad y seguridad personal, consagrado en la legislación interna e internacional. ${ }^{14}$

Esta situación internamente no es nueva para Colombia ni tampoco en el plano internacional, como dan cuenta las sentencias proferidas en su contra por la Corte Interamericana de Derechos Humanos, cuyo común denominador es la omisión del deber de protección de derechos fundamentales relativos a la libertad y seguridad personal.

Con relación a las ST, encontramos que, en el período de gobiernos posconstitucionales, la cC revocó el 40\% de fallos expedidos en instancias anteriores relativos a la libertad personal, para conceder el amparo; siguiendo la misma tendencia, pero con un aumento significativo en el período de PSD, revocó un 54\% de fallos de instancias anteriores, con el mismo propósito.

consultarse el artículo sobre el carácter de la Constitución colombiana a partir de una clasificación que establece Mauricio García Villegas, según la cual las constituciones están enmarcadas entre el constitucionalismo aspiracional, refiriéndose a la concepción que liga Constitución con progreso, y al constitucionalismo preservador como el que asocia la Constitución al mantenimiento del statu quo (García Villegas y Uprimny, 2006).

13 La Constitución colombiana de 1991 se enmarca en el modelo neoconstitucionalista, en el sentido de acoger, a través de sus mismas reglas y posteriormente desarrollado vía jurisprudencial, insumos del positivismo, otorgando fuerza vinculante a los precedentes en materia de constitucionalidad y del iusnaturalismo, incorporando la cláusula de ampliación de derechos consagrada en el artículo 94 de la Carta, que señala de manera expresa que "la enunciación de los derechos y garantías contenidos en la Constitución y en los convenios internacionales vigentes, no debe entenderse como negación de otros que siendo inherentes a la persona humana, no figuren expresamente en ellos".

14 En el ámbito interno, el artículo 13 de la Constitución colombiana reconoce el derecho a la libertad y seguridad personal de manera simultánea al reconocimiento del derecho a la igualdad; de la misma forma, este derecho también se consagra en el preámbulo y está implícito en toda la declaración de derechos. En el plano internacional, este derecho se reconoce en diversos instrumentos internacionales suscritos por Colombia, entre los que podemos enunciar: Pacto Internacional de Derechos Civiles y Políticos de 1966; Convención Americana sobre Derechos Humanos; Protocolo Adicional a la Convención Americana sobre Derechos Humanos en Materia de Derechos Económicos, Sociales y Culturales o Protocolo de San Salvador; Convención Interamericana para Prevenir y Sancionar la Tortura; Convención Interamericana para Prevenir, Sancionar y Erradicar la Violencia contra la Mujer, Convención Belém do Pará; Convención Interamericana sobre Desaparición Forzada de Personas; Convención Interamericana para la Eliminación de Todas las Formas de Discriminación contra las Personas con Discapacidad. 
Conforme con estas estadísticas, hallamos en las ST sobre la libertad y seguridad personal el mayor número de sentencias proferidas por la CC, tanto en el período 2002-2010 como en los períodos de gobiernos posconstitucionales $1991-2001 ;{ }^{15}$ sin embargo, en el período PSD, observamos un aumento en el porcentaje de revisiones, que asociamos a la ejecución de la PSD, no obstante ser un período menor, es decir: en ocho años se solicitó más protección en torno a la vulneración del derecho a la libertad y seguridad personal que en toda una década.

De la misma manera, se observó otro fenómeno importante: en los dos períodos de referencia, la CC, para proteger las libertades, revocó, en un porcentaje considerable, fallos de instancias anteriores que negaban la protección solicitada y amparó las libertades vulneradas. Incluso, se evidencia que revocó un número considerable de fallos a la CSI, lo que deja entrever la diversidad de los enfoques y alcance de protección de las libertades por parte de la jurisdicción ordinaria y la jurisdicción constitucional.

Entre las 133 sentencias expedidas frente a la libertad personal, durante el período de PSD, 84 fueron $\mathrm{ST}^{16}$ y 49, SC. $^{17}$

15 Aclaramos aquí que es el derecho sobre el cual se solicita mayor protección dentro del ámbito de las libertades, ya que el derecho por el cual se solicita mayor protección de acuerdo con los tres tipos de derechos que consagra la Constitución colombiana (libertades, derechos sociales económicos y culturales, y derechos colectivos) es el derecho a la salud integral, según cifras oficiales dadas por la Defensoría del Pueblo en el período en el cual se realizó esta investigación y que sigue constante conforme con una revisión realizada en el año 2012. Véase: Defensoría del Pueblo. Informe: La tutela y el derecho a la salud. Recuperado de http://www.defensoria.org.co/red/anexos/ publicaciones/tutelaDerechoSalud2012.pdf

16 ST-062/02, ST-362/02, ST-839/02, ST-455/04, ST-679/04, ST-684/04, ST-321/05, ST659/05, ST-1069/05, ST-406/06, ST-693/06, ST-1085/06, ST-133A/07, ST-1032/07, ST-957/06, ST-719/03, ST-596/04, ST-899/04, ST-659/05, ST-1303/05, ST-524/05, ST-634/05, ST-683/05, ST-686/05, ST-1257/05, ST-212/06, ST-439/06, ST-1037/06, ST-808/06, ST-1032/07, ST-715/07, ST-824/07, ST-895/07, ST-496/08, ST-1101/08, ST-1254/08, ST-578/10, ST-339/10, ST-728/10, ST-134/10, ST-223/02, ST-493/03, ST-1239/04, ST-723/06, ST-724/06, ST-780/05, ST-865/06, ST-434/07, ST-444/07, ST-393/08, ST-479/10, ST-096/04, ST-888/10, ST-372/10, ST-217/10, ST-113/09, ST-774/08, ST-661/08, ST-436/08, ST-786/07, ST-226/07, ST-1055/06, ST-1023/05, ST-1168/05, ST-676/05, ST-694/05, ST-484/05, ST-521/05, ST-274/05, ST-1035/04, ST-853/04, ST-804/04, ST-1047/03, ST-1082/03, ST-338/04, ST-722/02, ST-785/02, ST-868/02, ST-894/02, ST-895/02, ST-268/03, ST-310/03, ST-190/02 y ST-195/02.

17 SC-1024/02, SC-478/03, SC-101/05, SC-237/05, SC-730/05, SC-1001/05, SC-176/07, SC-479/07, SC-226/08, SC-318/08, SC-425/08, SC-316/02, SC-371/02, SC-580/02, SC-805/02, SC-251/02, SC-688/02, SC-430/03, SC-530/03, SC-622/03, SC-1056/04, SC-863/04, SC850/05, SC-1260/05, SC-187/06, SC-291/07, SC-720/07, SC-226/08, SC-1198/08, SC-185/02, SC-284/02, SC-713/02, SC-039/03, SC-123/04, SC-806/02, SC-194/05, SC-239/05, SC-665/05, SC-189/08, SC-400/06, SC-204/05, SC-528/03, SC-984/02, SC-030/03, SC-184/03, SC-416/02 y SC-296/02. 
Para presentar los resultados de la investigación, realizamos el análisis bajo las categorías de sujetos protegidos y órdenes de protección expedidas por la $C C$; en este orden, encontramos, y presentamos a continuación, sentencias sobre sujetos de especial protección constitucional: población desmovilizada de la guerra y reinsertada a la vida civil, desplazados por la violencia, activistas de derechos humanos, sujetos protegidos en razón a las labores que ejercen y sujetos amparados con medidas de protección de la Comisión Interamericana de Derechos Humanos.

\subsection{Protección a los desmovilizados de la guerra}

Para iniciar este análisis, y poner de presente el activismo judicial de la CC como institución en su proceso de interpretación evolutiva y creativa de la CP, escogimos la ST-719/03 porque permitió el despliegue de todos los presupuestos jurisprudenciales que determinan el alcance del derecho a la libertad y seguridad personal frente a los actores que participan de la guerra irregular, y recuerda el compromiso gubernamental en torno a su protección.

Esta sentencia, con ponencia del magistrado Manuel José Cepeda, merece especial relevancia por varias razones: fue la primera expedida después de casi un año de la ejecución de la PSD; en ella, la CC sancionó la burocracia del Estado colombiano alrededor de procesos agenciados para la obtención de la paz, que generan por sí mismos un alto porcentaje de ineficacia e impiden que la sociedad colombiana salga del nido de dolor causado por la violencia en el que se mantiene sumida desde hace más de 60 años. ${ }^{18}$ Así mismo, llamó la atención de los jueces constitucionales por la indebida interpretación de la CP, entre los que se incluye a la CSJ, ya que desconocen los actuales postulados del constitucionalismo contemporáneo en ella establecidos desde hace 20 años, incluso debidamente desarrollados por la CC, que implican una labor judicial activa y crítica frente a las leyes

18 Ángela Uribe Botero (2009) presenta en su libro Perfiles del mal en la historia de Colombia, bajo un análisis de casos que van desde el Nuevo Reino de Granada hasta el siglo xx, la forma como se ha construido el concepto de adversario que ha generado los altos niveles de crueldad utilizados por los diferentes actores de la guerra, que se constituye en otro de los factores determinantes para la difícil superación de esta y el mantenimiento de la miseria en torno al sujeto humano. 
ineficaces y la falta de garantías de protección de los derechos constitucionales de los asociados.

Otra razón para la elección de esta sentencia es el alcance del derecho a la libertad y seguridad personal, en el sentido de que se amplía para cobijar no solo a los reinsertados a la vida civil, sino también al núcleo familiar, al que lo extendió con todas las garantías. Finalmente, tuvimos en cuenta que la CC, atribuyendo un significado nuevo al alcance del derecho a la libertad y seguridad personal, materializó todo un proceso de interpretación tanto creativa como dinámica en la medida en que interpretó este derecho de acuerdo con la evolución de los hechos históricos del país.

El caso del que parte la ST es la solicitud de tutela a la vida y libertad personal que presenta la viuda y el hijo menor de edad de un reinsertado de la guerrilla de las FARC, asesinado a causa de la omisión del deber del Estado de otorgarle mínimas condiciones de seguridad, dados los riesgos extraordinarios y vulnerabilidad que conllevaba su apuesta a la paz con la desmovilización. ${ }^{19}$

Las instancias anteriores que conocieron la solicitud de tutela la negaron: en primer lugar, el $1^{\circ}$ de octubre de 2002, la negó el Tribunal de Bogotá; la impugnación de esta decisión la conoció en segunda instancia la CSI, que, de igual forma, negó la solicitud argumentado que la tutela no era la vía para solicitar un amparo de tipo económico. La CSJ (2003) se pronunció así:

Las omisiones en las que pudieron haber incurrido las autoridades públicas en relación con el asesinato del señor Betancur Montoya no se pueden evaluar por vía de tutela; los continuadores de su personalidad podrán, si así lo estiman conveniente, acudir ante la jurisdicción ordinaria competente para hacer efectivas las indemnizaciones que se pretendan y que se hayan originado en acción u omisión del Estado (...). El juez constitucional no se puede pronunciar sobre un derecho incierto como el que se invoca.

19 Los hechos de este caso se resumen en la solicitud de protección a la vida y seguridad personal de la compañera y el hijo, menor de edad, de un desmovilizado de las FARC, reinsertado a la vida civil y luego asesinado por la omisión del Estado de otorgarle un esquema de seguridad para enfrentar las amenazas contra su vida por parte de excompañeros de las FARC, junto a la solicitud de pago del seguro de vida a que tenían derecho los accionantes. 
El garantismo constitucional, que pretendemos demostrar, se evidencia en que, precisamente, la CC revocó los fallos de instancias anteriores bajo la consideración de que el problema por resolver no versaba sobre los aspectos económicos derivados de la existencia o reconocimiento de pago del seguro de vida del reinsertado asesinado, sino, por el contrario, del deber de protección a la libertad y seguridad personal de su núcleo familiar sobreviviente. La CC consideró que se les debían extender a la familia las prerrogativas otorgadas por el gobierno al reinsertado y protegerse sobre todo el derecho a la libertad y seguridad personal que estaba siendo violado, aspectos que no especifican los jueces de instancias anteriores, entre los cuales se cuenta la CSJ.

Tanto es así que la CC, al asumir la revisión del caso, señaló como problema jurídico por resolver:

Si bien las pretensiones formuladas por la actora en su demanda se refieren a (i) la efectividad de una póliza de seguros que, según lo dispuesto en la ley, debía amparar a su difunto compañero permanente, (ii) la iniciación de investigaciones contra algunos funcionarios públicos, (iii) la provisión de condiciones de seguridad aptas para ella y su hijo, a través de la reubicación, y (iv) el suministro de ayuda económica por parte de la Dirección General para la Reinserción, la Sala considera que el caso bajo revisión plantea problemas jurídicos constitucionales de mayor alcance y complejidad, en relación con el trato del que era merecedora la peticionaria por su triple calidad de (a) compañera permanente supérstite de un individuo reinsertado a la vida civil después de haber pertenecido a la guerrilla, (b) víctima civil de la violencia armada que afecta al país, por haber perdido un familiar con motivo del conflicto, $y$ (c) mujer cabeza de familia desplazada por la violencia, madre de un niño de menos de un año de edad, en condiciones de extrema pobreza y vulnerabilidad manifiesta [letra cursiva agregada] (ST-719/03, M. P. Manuel José Cepeda).

Bajo la reconceptualización del problema jurídico por resolver, la CC se pronunció en esta ST sobre el alcance, ámbito de aplicación y límites al derecho a la libertad y seguridad personal; sobre la teoría de riesgos desde las jurisdicciones contenciosa administrativa y constitucional; y sobre la especial protección establecida en la Carta a la población reinsertada en la guerra irregular de Colombia. 


\subsection{Población desplazada por la violencia}

En la ST-268/03, se configuran los desaciertos del poder judicial y la falta de atención del poder ejecutivo frente a sujetos de especial protección constitucional, así como el garantismo judicial que adelanta la CC colombiana.

Esta sentencia parte de una acción de tutela presentada por la Defensora del Pueblo, regional del departamento de Antioquia, mediante la cual solicitó la protección a la libertad y seguridad personal de 65 familias desplazadas por la violencia.

Al igual que la ST-719/03, el amparo fue negado por los jueces de instancias anteriores, entre los que nuevamente se registra la intervención de la CSJ, quienes, sujetos a un positivismo extremo, alegaron la obligatoriedad de que las personas en circunstancias de desplazamiento cumplieran los requisitos señalados en el artículo 13 del Decreto 2569/00, que hace referencia a la necesariedad de rendir una declaratoria individual sobre los hechos de los que han sido víctimas para obtener protección.

En este caso, la CC también recurre a una interpretación evolutiva y creativa y concede la protección, luego de la presentación de lo que se convertiría en los precedentes sobre protección a personas desplazadas de mayor relevancia en el país, en tanto indica que, antes del cumplimiento de un requisito administrativo, y ante la particular situación de Colombia, sobre estos sujetos recae el principio constitucional de buena fe, que se constituye no solo en un mecanismo de protección, sino en una garantía ante las dilaciones que las autoridades administrativas aleguen para retardar el cumplimiento de su función constitucional de protección. La CC sostiene de manera específica:

La Corte reitera en esta ocasión que el juez de tutela no puede invocar circunstancias formales (no provenientes de omisión de los afectados) para negar la protección a derechos fundamentales de los desplazados. Además, en gracia de discusión, el mismo Decreto 2569 de 2000, trae unas normas especiales que por tal característica y dado su carácter de favorabilidad, debe aplicarse de preferencia en el evento de existir desplazamiento masivo, como ocurre en el presente caso. Nótese que el caso de la presente tutela se ubica dentro de esta norma especial, puesto que fueron 65 familias y alrededor de 400 personas (...). No es justo que si no se expide la 
certificación por la Red de Solidaridad, se crea que una persona no tenga la condición de desplazado. Si lo válido únicamente fuera tal certificación, los derechos fundamentales de los desplazados se estarían condicionando, en cuanto a su exigibilidad al mencionado certificado. El no otorgamiento por las autoridades del correspondiente certificado de desplazado a quien tiene derecho a él, es una violación a derechos fundamentales como lo ha sostenido la jurisprudencia constitucional. La Corte ha dicho que existe una presunción de buena fe y necesidad de trato digno en el trámite de inscripción en el Registro Nacional de Desplazados (ST-268/03, M. P. Marco Gerardo Monroy Cabra).

Otro caso donde se protege a población desplazada se configura con la ST-1101/08;20 en esta sentencia, vuelve la CC a revocar el fallo anterior expedido por la CSI que negó la protección, y concede el amparo, incluso antes de conocer el resultado de un estudio de riesgos, bajo la consideración de que los trámites administrativos no pueden, de ninguna manera, dilatar la protección de sujetos en situación de riesgo extraordinario. Al iniciar el análisis, la CC se plantea como problema por resolver: ¿resulta atendible la solicitud de amparo del derecho fundamental a la seguridad personal por vía de tutela, cuandoquiera que a favor del titular de la garantía se ha iniciado un procedimiento administrativo de valoración de riesgo para efectos de obtener una conclusión definitiva a propósito de la necesidad de proteger de manera definitiva su seguridad?

Frente a esta pregunta, la CC desarrolla el siguiente precedente:

En atención a las gravosas circunstancias en las cuales se encuentra la accionante -las cuales incluyen el padecimiento de graves hechos constitutivos de tortura-, no es admisible que la entidad demandada no se

20 La ciudadana C. C. interpuso acción de tutela contra el Ministerio del Interior y de Justicia con el objetivo de obtener amparo judicial de sus derechos fundamentales a la vida digna, la integridad personal y la libertad de locomoción; la accionante afirma que hasta el día 15 de octubre de 2007 habitaba en compañía de sus cuatro hijos en el departamento de Tolima, del cual debió partir debido a amenazas provenientes de miembros del Frente 21 de las FARC. Indica que en dicha oportunidad fue víctima de actos de tortura - de manera puntual afirma que sufrió desfiguración de su rostro y amputación de dos dedos de su mano derecha-. La señora C. C. sostiene que, en atención a que la autoridad demandada no ofrecía respuesta a su solicitud de concesión de medidas de protección, se vio obligada a retornar a la ciudad de Ibagué el día 29 de febrero de 2008, donde fue abordada una vez más por miembros del Frente 21 de las FARC, quienes reiteraron las amenazas que ya habían realizado y forzaron a la señora C. C. a abandonar de manera inmediata el lugar, razón por la cual estuvo de vuelta en la ciudad de Bogotá. 
haya pronunciado de manera definitiva sobre la solicitud de inclusión en el programa de protección, la cual fue radicada el día 20 de febrero de 2008. Sobre el particular, la Sala observa que la severidad de la amenaza, que ya en precedencia provocó el desplazamiento forzado de la accionante y de los demás miembros de su grupo familiar, hace evidente que el transcurso de un término superior a siete meses para la definición concluyente sobre la necesidad de conceder medidas especiales de protección pone en grave riesgo a la demandante y a sus familiares de sufrir severos padecimientos y vulneraciones de sus derechos fundamentales (ST-1101/08, M. P. Humberto Antonio Sierra Porto).

Con la ST-895/07,21 la CC se pronuncia sobre dos circunstancias: la primera es la situación de desplazamiento de la accionante y la segunda, los trámites administrativos que exigen las autoridades administrativas del Estado para otorgar la protección humanitaria, establecida en programas oficiales, a las víctimas de la violencia. En este caso, la CC expresó:

Teniendo en cuenta que la valoración de los hechos expuestos por la accionante debe hacerse a partir del principio de la buena fe, correspondía a Acción Social desvirtuar tales afirmaciones, pues la carga de la prueba para demostrar la existencia de la amenaza en cabeza de la actora o su familia, esta última que permanece aún en la región, la tiene la entidad ya que es quien cuenta con medios suficientes para verificar la situación social de los lugares de Colombia de donde manifiestan las personas que fueron desplazados, así como las fechas en que ello supuestamente ocurrió. Además, pueden también determinar sumariamente los lugares del país en donde tienen influencia los actores armados (ST-895/07, M. P. Clara Inés Vargas Hernández).

Con la ST-134/10, ${ }^{22}$ la CC revoca la decisión anterior de la CSJ y concede el amparo de un activista de derechos humanos que se ve obligado a

21 La señora Julia Emma Garcés Arcila interpuso acción de tutela contra la Agencia Presidencial para la Acción Social y la Cooperación Internacional -Acción Social-, al estimar que dicho ente gubernamental vulneró sus derechos fundamentales a la vida digna, de petición y a "recibir protección del Estado", al negar, "por considerarla extemporánea", su solicitud "de ayuda humanitaria y/o indemnización" con ocasión de la "muerte violenta" de su hija mayor de edad.

22 El actor se desempeña como defensor de derechos humanos y director nacional de la Corporación Colombiana de Desplazados; debido a su trabajo, ha recibido amenazas de muerte, por lo 
desplazarse por las amenazas derivadas de su obrar. La CC nuevamente acude a la teoría de riesgos para conceder la protección:

Los antecedentes de amenaza contra la vida e integridad del accionante, que repercuten hacia su familia, obligan a que, por razones de cautela, se asegure continuidad en la protección que el Estado debe otorgarle y que se minimicen los riesgos que pudiese traer consigo la variación en el tipo de seguridad que se venía prestando, de manera que por falta de precauciones o cambios abruptos en la modalidad, y más todavía al suprimírsele, se posibilite la consumación de las amenazas (ST-134/10, M. P. Nilson Pinilla Pinilla).

\subsection{Activistas de derechos humanos}

Con la ST-327/04, ${ }^{23}$ la CC tutela los derechos a la libertad personal de los miembros de la Comunidad de Paz de San José de Apartadó, como sujetos sometidos a riesgos extraordinarios y especiales circunstancias de vulnerabilidad, que les habían sido negados por las instancias anteriores; $\mathrm{y}$

cual tuvo que trasladarse junto con su familia a la ciudad de Bogotá; se le proporcionó un sistema de seguridad con escolta, pero, después de llevarse a cabo la valoración de riesgos, fue desvinculado del programa de seguridad, pese a ello las amenazas contra su vida son permanentes. Con la tutela solicitó que se revoque la orden de retirar el esquema de seguridad para él y su familia.

23 El demandante, Javier Giraldo Moreno S.J., coadyuvado por la Defensoría del Pueblo, manifiesta que se han dado graves hechos que indican que se está llevando a cabo un plan desde la Brigada XVII encaminado a desprestigiar y eliminar a los integrantes de la Comunidad de Paz. Prueba de ello fueron los sucesos ocurridos con el integrante de la Comunidad Lubián Tuberquia, a quien, el día 7 de febrero de 2003, dos personas vestidas de civil, que se identificaron como el General y el Teniente, le propusieron que, para que fuera excluido de la lista de 'milicianos', que para ellos son quienes colaboran con la guerrilla, debía trabajar con el Ejército, acusando a los líderes de la Comunidad de Paz, lo que no aceptó. Además, en la misma reunión vio en una lista a los nombres de miembros de la Comunidad y oyó cómo se concertaba un plan para que sus líderes fueran sometidos a procesos judiciales, que implicaran privación de la libertad o, si esta estrategia fallaba, esas mismas personas fueran asesinadas por los paramilitares. La denuncia sobre estos hechos la realizó Lubián Tuberquia ante la Fiscalía General de la Nación, Unidad Nacional de Derechos Humanos y Derecho Internacional Humanitario, en la ciudad de Bogotá, el día 21 de febrero de 2003. Para el demandante, los hechos ocurridos en el retén que se realizó el día 12 de febrero de 2003, en la carretera entre Apartadó y San José de Apartadó, en el que fueron capturadas nueve personas, varias de las cuales son integrantes de la Comunidad de Paz, y una de ellas continúa privada de la libertad, por haber encontrado en el vehículo de servicio público en que se transportaban una caja con explosivos y un papel escrito a mano dirigido a una persona llamada Amanda, le dan el convencimiento de que el plan está en ejecución, dadas las extrañas circunstancias que se presentaron para 'encontrar' el paquete. Lo que más preocupa al demandante es la que denomina 'práctica de compra de testigos' y, para la población, la manera como se conforman las 'listas de milicianos', al parecer, a partir de las retenciones de documentos de identidad. 
bajo la particularísima circunstancia de ser un grupo protegido por la Corte Interamericana de Derechos Humanos.

La CC sigue insistiendo en el llamado de atención a las autoridades que dilatan la protección de estos sujetos por trámites administrativos y concede el amparo solicitado bajo el siguiente argumento:

La Corte Constitucional concederá esta acción de tutela, mientras culmina el procedimiento de adopción de medidas cautelares a nivel nacional por parte de las más altas autoridades del Estado, con el fin de que cesen las perturbaciones a la Comunidad. Para tal efecto, procederá a proteger a los individuos que integran la Comunidad de Paz de San José de Apartadó, impartiendo unas órdenes a nivel regional, encaminadas no sólo a aminorar el temor de los habitantes de San José de Apartadó y de quienes tienen vínculos de servicio con la Comunidad, sino para proteger sus derechos fundamentales mencionados, pues el juez de tutela no puede denegar la solicitud de tutela simplemente porque las autoridades nacionales no han finalizado el proceso de adopción de medidas cautelares ordenadas por la Corte Interamericana, dado que los hechos indican que existen amenazas de violación de los derechos humanos de la Comunidad de Paz y de quienes tienen vínculos de servicio con la Comunidad (ST-327/04, M. P. Alfredo Beltrán Sierra).

Sin embargo, no solo se pronuncia sobre la orden de protección, también hace un llamado a las autoridades, recordando el carácter de garante que tienen las FF. MM.

“Es de observar que el Comandante de la Brigada XVII del Ejército no solo debe responder por las actividades del personal bajo su mando, sino por las omisiones en que este incurra. Es decir, se le reconoce la posición de garante de quien tiene bajo su comando una Brigada del Ejército $\mathrm{Na}-$ cional" (ST-327/04, M. P. Alfredo Beltrán Sierra).

En la ST-496/08, ${ }^{24}$ la CC concede protección especial al colectivo de mujeres Alianza Iniciativa de Mujeres Colombianas por la Paz (IMP), quienes,

24 Acción de tutela: instaurada por Patricia Buriticá Céspedes en nombre propio y en representación de Alianza Iniciativa de Mujeres Colombianas por la Paz (IMP) y de otras mujeres víctimas de la violencia contra el Ministerio del Interior y de Justicia y la Fiscalía General de la Nación. En su sentir, las entidades accionadas han desconocido los mencionados derechos al no implementar un programa específico y suficientemente efectivo de atención a las víctimas de los conflictos de esta 
en razón a su activismo, han sido sometidas a amenazas y, en algunos casos, han sido asesinadas.

Aquí se pone de presente el choque de trenes entre las altas cortes, ya que la CC revisa la decisión del CE de no amparar los derechos de las acciones, argumentando que la acción de tutela no era el mecanismo idóneo para solicitar la protección; ante esto, la CC

recordó que el derecho a la seguridad personal tiene el carácter de fundamental en el contexto colombiano; constató que las demandantes tienen la condición de víctimas del conflicto, de gestoras de procesos de reivindicación y residen en zonas del país calificadas como de extraordinario y alto riesgo, circunstancia que las ubica en una situación de amenaza de sus derechos fundamentales a la seguridad, la libertad, la integridad personal y la vida, y de evidente vulneración de su derecho a acceder con plenas garantías a los procesos en procura de satisfacer sus derechos a la verdad, la justicia y la reparación; verificó así mismo que las actoras se encuentran en la situación de especial vulnerabilidad que plantea su condición femenina debido al impacto diferenciado y a las cargas extraordinarias que deben soportar en virtud de esa condición, en el contexto de la confrontación armada; constató que la estrategia de protección a víctimas y testigos de los procesos de justicia y paz no incorpora este enfoque diferencial basado en el género, como tampoco otros enfoques diferenciales basados en factores como la edad, la etnia, o la salud; recordó que este enfoque diferencial resulta imperativo frente a las múltiples obligaciones constitucionales e internacionales que exigen acciones encaminadas a la protección de la mujer contra toda violencia y a prevenir y enfrentar la violencia estructural que ha soportado históricamente, así como la violencia magnificada como consecuencia del conflicto [letra cursiva agregada] (ST-496/08, M. P. Jaime Córdoba Triviño).

Otro caso en que la CC revoca la decisión anterior de la CSJ y protege derechos, en esta ocasión, de una fundación a favor de las víctimas del conflicto armado, que han sido amenazadas de muerte y señaladas como objetivo militar, es la ST-728/10. ${ }^{25}$ La CC acude a la teoría de riesgos para conceder la protección.

entidad. Con el propósito de hacer más ostensible la gravedad del asunto, hicieron una relación de eventos en los cuales mujeres propulsoras de estos movimientos han sido asesinadas, amenazadas o lesionadas.

25 Los demandantes forman parte de una organización sin ánimo de lucro denominada Fun- 
Relacionamos aquí las ST expedidas a partir de la solicitud de protección de sujetos sometidos a riesgos extraordinarios; con estas sentencias, se pone de presente la protección judicial al derecho a la libertad y seguridad personal, por parte de la CC.

Con la ST-377/03, ${ }^{26}$ la CC revocó la sentencia de segunda instancia y confirmó la de primera instancia concediendo el amparo, bajo el argumento de la especial situación de vulnerabilidad en la que se encontraba la accionante, argumentando: "Al evidenciarse que la vida de la actora corre peligro en el departamento de Nariño, las autoridades accionadas tienen el deber moral e institucional de participar en la protección de este derecho inalienable, a través de su reubicación [...]. Además, el derecho a la vida no puede depender de un trámite administrativo ni del capricho del funcionario de turno" (ST-377/03, M. P. Jaime Córdoba Triviño).

Otra sentencia en el mismo sentido es la ST-804/04, ${ }^{27}$ mediante la cual también se protege a una persona sometida a riesgos excepcionales que no

dación Humanitaria Manos Unidas por Colombia (Fhumucol), con sede en la ciudad de Bogotá, dedicada a "prestar asistencia psicológica, jurídica, espiritual y de derechos humanos a las víctimas del conflicto armado, y de crímenes de Estado". Informan que como consecuencia de su actividad han recibidos amenazas telefónicas provenientes de grupos emergentes del paramilitarismo conocidos como 'Águilas Negras', en las que se les señala como objetivo militar. Sostienen que esta situación "los mantiene aterrorizados y en una situación de persecución y desplazamiento", hecho que han denunciado ante diversas autoridades nacionales, como la Procuraduría General de la Nación, la Fiscalía General de la Nación, Acción Social, el Congreso de la República, el Alto Comisionado de las Naciones Unidas para los Derechos Humanos y otras organizaciones internacionales (ST728/10, M. P. Luis Ernesto Vargas Silva). Por tales razones, los actores interpusieron acción de tutela contra el Ministerio del Interior y de Justicia, al considerar vulnerados sus derechos fundamentales a la vida, intimidad, igualdad, protección de la familia, libertad, debido proceso, trabajo y derechos fundamentales de los niños.

${ }^{26}$ La accionante, Martha Lucía López Pabón, instauró acción de tutela para solicitar el amparo de sus derechos a la vida, la libertad, el trabajo y petición, los cuales considera vulnerados con la decisión de las secretarías de educación de los departamentos de Nariño y del Valle del Cauca, que niegan su traslado, por permuta con otro docente nacionalizado, para reubicarla de manera definitiva en una localidad lejana a aquella en la que está amenazada su vida.

27 La accionante instaura acción de tutela en contra del Programa de Protección de la Dirección General para los Derechos Humanos del Ministerio del Interior y de Justicia, puesto que considera que el estado de peligro en que se encuentra le da derecho a demandar protección especial, así la Dirección General para los Derechos Humanos del Ministerio haya considerado: "Que no se ajustaba mi petición a los parámetros de la precitada ley, ya que las amenazas tenían origen a mi profesión de abogada y me encontraba expuesta a ello [sic]". Expone que sus derechos a la vida, libertad, integridad y seguridad personal están siendo desconocidos, dado que las situaciones de riesgo puestas en conocimiento de las autoridades, y algunas no denunciadas, así lo demuestran. 
está obligada a soportar y ante una evidente situación de vulnerabilidad, derivada del ejercicio de su profesión como abogada, del deber constitucional de denunciar actividades ilícitas, y frente a la cual no obtiene una respuesta eficaz de las autoridades en torno a la protección a su libertad y seguridad personal. En este caso, la CC resalta la labor de información de la accionante y ordena la protección, revocando una vez más el fallo de la instancia anterior que había negado la protección. En esta ST, la CC

[...] concede la protección, en cuanto la accionante actúa en ejercicio de un deber constitucional y así permite que el Estado investigue las conductas, sancione a los responsables e indemnice a las víctimas de conductas criminales. De lo que se infiere que las cuestiones relativas a la seguridad de los abogados, en cuanto se orientan a garantizar su independencia de la cual pende en gran medida la eficacia de su gestión, que redunda en hacer realidad la garantía constitucional del debido proceso, deberán estar comprendidas en las medidas especiales, en torno de los derechos humanos que el Estado está en el deber de promover y hacer efectivas (ST-804/04, M. P. Álvaro Tafur Galvis).

Con la ST-683/05, ${ }^{28}$ la CC protege a una ciudadana que denuncia la venta de estupefacientes en un lugar cercano a su residencia y revoca la decisión de la CSJ, que en instancia anterior negó la tutela.

Se detiene en ellas: asegura haber suministrado informaciones importantes a las autoridades sobre hechos delictivos, atribuidos a grupos alzados en armas, y relata las solicitudes de protección personal presentadas a los organismos responsables de su seguridad, que no han sido atendidas.

28 La ciudadana Myriam Serna Correa estima que el Ministerio de Defensa y la Policía Nacional han vulnerado sus derechos fundamentales a la vida y a la integridad personal, al no adoptar las medidas adecuadas y necesarias para garantizar su seguridad personal. Según la actora, lo anterior obedece a un caso de corrupción que se presenta en estas instituciones, lo cual ha imposibilitado la actuación de las autoridades frente a las denuncias hechas por ella, relativas al expendio de estupefacientes en un lugar cercano a su residencia. Las entidades demandadas afirman no haber incurrido en violación de los derechos fundamentales de la actora. La primera, por cuanto brindó la atención solicitada por la ciudadana Serna Correa y, la segunda, bajo el argumento de haber adelantado las actuaciones pertinentes en relación con: (i) la judicialización de los presuntos expendedores de narcóticos y (ii) la protección de la seguridad personal de la actora, de acuerdo con los resultados arrojados por el estudio de seguridad y nivel de riesgo de esta. Estima que la sentencia de primera instancia no incurre en defectos de motivación, sino que la acción de tutela, así como la impugnación del fallo de primera instancia, obedecen a la disconformidad de la señora Serna Correa frente a las medidas implementadas por la Policía respecto de la protección de su seguridad, las cuales estima insuficientes, considera que no se evidencia vulneración por parte de las entidades demandadas de los derechos fundamentales de la peticionaria, pues, a su juicio, las actuaciones de estas han sido adelantadas de forma diligente y tomadas con base en su nivel de riesgo. 
La importancia de esta sentencia radica en que la CC recuerda el deber constitucional de colaboración para el buen funcionamiento de la administración de la justicia, especificando las siguientes características: "(i) Se trata de un deber positivo consagrado en la Carta Constitucional; (ii) es universal, ya que vincula a todos los individuos sometidos al ordenamiento jurídico nacional; (iii) es un deber no retribuido, pues no supone recompensas por parte del Estado; y (iv) este deber se deriva de la obligación de organización del poder y de la defensa de las libertades ciudadanas" (ST-683/05, M. P. Humberto Antonio Sierra Porto).

En el mismo sentido, recuerda a la Fiscalía General de la Nación los criterios para la vinculación en el Programa de Protección a Testigos, Víctimas, Intervinientes en el Proceso:

Los criterios que rigen la vinculación al Programa son los siguientes: (i) que exista nexo entre la participación en el proceso penal de quien aspire a ingresar al Programa y los factores de amenaza y riesgo; (ii) que la única motivación que haya impulsado (a quien aspire a la protección) a participar en el proceso penal sea la de colaborar oportuna y espontáneamente con la administración de justicia; (iii) que el tipo de medidas de seguridad no pueda ser implementado por otro organismo estatal creado con esa finalidad o que las medidas requeridas correspondan a las específicas del Programa; (iv) que la admisión del candidato a ser protegido no constituya un factor que afecte en forma insuperable la seguridad de la estructura del Programa o de la propia Fiscalía General de la Nación (ST-683/05, M. P. Humberto Antonio Sierra Porto).

En razón a su cargo de personero municipal, agente del Ministerio Público, órgano encargado de velar por la protección de los derechos fundamentales de la población, la CC expidió la ST-686/05, ${ }^{29}$ mediante la cual no concedió el amparo porque consideró estarse frente a un hecho superado; sin embargo, aludió a la necesaria protección de los funcionarios

29 El accionante Humberto Elías Arismendy Cuadros, en calidad de Personero del municipio de Hispania, interpuso acción de tutela para que le sean protegidos sus derechos fundamentales a la vida, al trabajo, a la integridad física, a la igualdad y a la dignidad humana, que -según afirmaestán siendo vulnerados por la Mesa Directiva del Concejo Municipal de la citada entidad territorial, pues, no obstante conocer las graves amenazas en su contra, se negó injustificadamente a autorizar su reubicación laboral, temporal e indefinida, en la cabecera de otro municipio, a fin de permitirle adelantar desde alli el ejercicio de sus funciones. 
públicos que se encuentran sometidos a riesgos extraordinarios por la labor que ejercen. La CC consideró:

En ciertos casos se exige como carga ciudadana fundada en el principio de solidaridad social, que las personas asuman ciertos riesgos especiales, por fuera de los mínimos u ordinarios que se predican para toda la comunidad. Dichos riesgos por lo general tienen su origen en dos tipos de contingencias, por una parte, en aquéllas que se derivan de la convivencia en sociedad, por ejemplo, cuando para asegurar la defensa de una población es indispensable instalar una estación de policía, que por la situación interna de conflicto armado que vive el país, puede exponer a determinados riesgos a los vecinos de dichas construcciones; y por la otra, en aquéllas que subyacen a la prestación de los servicios públicos, ya sea en relación con las personas que se benefician de los mismos [sic], o frente a las personas encargadas de su prestación, es decir, los servidores públicos (ST-686/05, M. P. Rodrigo Escobar Gil).

Los miembros de los sindicatos también fueron sujetos de protección constitucional en cuanto su derecho a la libertad y seguridad personal; en la ST-1254/08, ${ }^{30}$ la CC confirma el fallo de instancias anteriores negando la solicitud de tutela, en el sentido de otorgarle al accionante el mismo trato que reciben sindicalistas de otras empresas, pero lo concede en cuanto a otorgar una protección que incluya, incluso, los permisos sindicales solicitados por el accionante. En todas estas sentencias, la CC insiste en recordar las características de los riesgos extraordinarios que los sujetos no están en la obligación de soportar. Reafirma la CC:

Las circunstancias en las cuales se puede invocar y hacer aplicable el derecho a la seguridad personal, en tanto derecho a recibir protección estatal frente a riesgos extraordinarios que el individuo no tiene el deber jurídico de soportar, dependen esencialmente del caso concreto, y deben ser evaluadas como un todo, desde una perspectiva integral, para establecer la naturaleza, alcance, intensidad y continuidad de los riesgos que gravitan sobre cada individuo. El funcionario competente, ante quien se haya puesto de

30 Solicitud de permisos remunerados a un sindicalista trabajador de la empresa Drummond Ltd., que se encuentra frente a riesgos extraordinarios y cuenta con un esquema de protección por parte del DAS, sobre el cual no ha manifestado ninguna queja. 
presente la situación de riesgo, deberá evaluar en el caso concreto si se trata de riesgos específicos, individualizables, concretos, presentes, importantes, serios, claros, discernibles, excepcionales y desproporcionados para el sujeto. Si detecta que están presentes todas estas características, y que además se trata de riesgos graves e inminentes, deberá dar aplicación a los derechos fundamentales a la vida e integridad personal; pero si están presentes algunas, y no todas, o unas con mayor fuerza que otras, manteniendo el riesgo su carácter extraordinario, habrá de dar aplicación al derecho a la seguridad personal, determinando las medidas procedentes (...). En este caso se puede concluir que los miembros de la subdirectiva seccional de Chiriguaná se encuentran probablemente en circunstancias de nivel de riesgo extraordinario, que no están obligados a soportar, razón por la cual tienen derecho a recibir una protección especial de las autoridades. Ciertamente, ellos son dirigentes de una organización sindical a la cual le han asesinado y amenazado varios líderes; actúan en una zona que ha sido extremadamente peligrosa durante muchos años para todos los que realizan actividades de reivindicación social y, además, en distintas ocasiones el presidente de la subdirectiva de Chiriguaná ha sido objeto de amenazas, hostigamientos y seguimientos [letra cursiva agregada] (ST1254/08, M. P. Manuel José Cepeda Espinosa).

Nótese que encontramos una diversidad de sujetos sometidos a una especial protección constitucional de acuerdo con las actividades que ejercen. En la ST-1037/08,31 la CC protege a una periodista amenazada y con

31 La señora Claudia Julieta Duque Orrego interpuso acción de tutela en contra del Ministerio del Interior y del DAS, por presunta vulneración de sus derechos a la vida, integridad personal y derecho a la familia, contenidos en los artículos 11, 12 y 42 de la Constitución. Cuenta que, como resultado de su trabajo como investigadora y periodista en temas de derechos humanos, viene siendo objeto de amenazas, hostigamientos, persecuciones y torturas psicológicas desde el año 2001 y que ha podido comprobar que en dichos hechos han participado organismos de seguridad del Estado, entre ellos el DAS. Para demostrar este aserto, aporta números de placas de automóviles y motos asociadas con estos organismos y nombres de terceras personas que pueden dar testimonio sobre la participación del DAS en algunos seguimientos de los que ha sido objeto. Considera que estos seguimientos y hostigamientos están relacionados con su investigación sobre el homicidio del periodista Jaime Garzón, investigación que le mereció una denuncia penal por injuria y calumnia por parte de un subdirector del DAS. Precisa que esta situación la ha llevado al exilio en dos ocasiones, a ser víctima de un secuestro y de múltiples hostigamientos y amenazas. Por esta razón, fue incluida en el Programa de Protección a Periodistas del Ministerio del Interior desde diciembre de 2003. Señala que las amenazas y hostigamientos se han trasladado a su hija menor. Contaba con un esquema de seguridad calificado como duro y compuesto por un carro blindado, dos teléfonos Avantel y un conductor de confianza. Protección que el Ministerio de Defensa ha decidido retirarle y sustituirlo por una ayuda económica para transportes. 
esquema de seguridad, confirmando el fallo de instancias anteriores que habían concedido el amparo; junto a esto, llama la atención a las autoridades del Estado en torno a la entrega de los informes de seguridad que el Departamento Administrativo de Seguridad (DAS) elabore, pues estos no están sometidos a reserva cuando se trate de los mismos afectados. Tal retención, junto a la violación a la libertad y seguridad personal, vulnera además el derecho a la intimidad en cuanto a la elaboración de los informes y el habeas data en cuanto a la negación de entregarlos a la persona afectada.

La elaboración de informes de inteligencia o de cualquier informe reservado que contenga información sobre la vida privada de la persona protegida y que no tenga relación con la situación de riesgo y las novedades del esquema de protección, vulnera, cuando menos, el derecho a la intimidad de la actora y de las personas sobre las cuales dichos reportes puedan versar. Adicionalmente, el hecho de que tales reportes no sean conocidos por el titular de la información vulnera su derecho al hábeas data. Una persona que ha solicitado y obtenido la protección del Estado por encontrarse en una circunstancia de riesgo extraordinario tiene derecho constitucional fundamental a conocer integralmente toda la información que sobre ella repose en los archivos de inteligencia y todos los reportes elaborados por las personas encargadas de protegerla, con excepción de aquella que haga parte de una investigación judicial que esté sometida a la reserva del sumario [...]. La elaboración y recepción de este informe y su administración reservada, al margen del conocimiento de la actora, vulnera los principios de libertad, necesidad, veracidad, integridad, incorporación, finalidad, utilidad y circulación restringida, explicados en el fundamento anterior de esta decisión (ST-1037/08, M. P. Jaime Córdoba Triviño).

Con la ST-372/10, ${ }^{32}$ la CC revoca el fallo anterior de la CSJ y concede el amparo a un desplazado por la violencia, que fue reclutado para prestar el servicio militar sin atender a su especial circunstancia. La CC consideró que ante su situación sí se configuraba la violación de derechos fundamen-

32 El accionante solicita el amparo de los derechos a la vida digna, libertad, y a recibir una protección especial por ser víctima del desplazamiento forzado. El señor actúa como agente oficioso de su hijo, el cual fue reclutado para prestar servicio militar, sin tener en cuenta su condición de desplazado, solicita se ordene el desacuartelamiento inmediato de su hijo y se le expida una tarjeta militar provisional, a la cual tiene derecho por ser parte de la población desplazada (ST-372/10, M. P. Luis Ernesto Vargas Silva). 
tales y ordenó que se le expidiera la tarjeta militar sin terminar de prestar el servicio.

Expidiendo órdenes de protección a sujetos sometidos a especial protección constitucional, la CC expide la ST-339/10,33 mediante la cual revocó las sentencias de instancias anteriores y tuteló el derecho, amparado en la teoría de riesgos y el principio de buena fe, de una persona que se había desempeñado como vocero de un proceso de paz y colaborador con las víctimas de la violencia, circunstancias que han generado la vulneración a su libertad y seguridad personal. En este caso, la CC manifestó:

La Sala estima que existe duda respecto del lugar que ocupa el peticionario en la escala de riesgos y amenazas antes estudiada. En efecto, por una parte, en virtud del principio de la buena fe, en principio, se debe creer en las afirmaciones hechas por el peticionario en el sentido de que está amenazado. Y, por otra parte, en el estudio de nivel de riesgo y grado de amenaza que se le realizó al actor, no se explica por qué, a pesar de que el peticionario afirmó haber recibido amenazas, este se encuentra en un nivel de riesgo y no de amenaza. Adicionalmente, en materia de seguridad personal, el peticionario es un sujeto de especial protección no solo por trabajar actualmente como defensor de derechos humanos sino también por tener la calidad de reinsertado del ELN. Por estos dos motivos y, teniendo en cuenta que lo que está en juego en la presente acción de tutela es el derecho a la seguridad personal del actor, la Sala estima conveniente ordenarle al Ministerio del Interior y de Justicia que, como medida provisional, equipe a los dos escoltas que protegen al peticionario de [dispositivos de comunicación] Avanteles y que ponga a su disposición un automóvil que le permita desplazarse con seguridad. Dicho automóvil deberá encontrarse en buenas condiciones mecánicas y los costos de su mantenimiento, incluyendo el seguro obligatorio, deberán ser sufragados por el Ministerio del Interior y de Justicia. Estas medidas deberán tomarse hasta que el Comité de Reglamentación y Evaluación de Riesgos corres-

33 El ciudadano Luis Alberto Cabeza Espinel interpuso acción de tutela contra la nación -Ministerio del Interior y de Justicia-, con el objetivo de obtener la protección de sus derechos fundamentales a la vida y a la igualdad, que habrían sido vulnerados. Al actor le fue asignado un esquema de seguridad por haber sido vocero público del proceso de paz de la corriente revolucionaria socialista y por su actividad social como defensor de derechos humanos, asesorando víctimas del conflicto armado; solicita se fortalezca su esquema de seguridad asignándole un vehículo en buenas condiciones, dotando a su equipo de Avanteles o celulares, y asumiendo el mantenimiento permanente del vehículo. 
pondiente, determine si el actor debe estar o no cobijado por el Programa de Protección de Derechos Humanos del Ministerio del Interior y de Justicia, regulado por el Decreto 2816 de 2006. Así, como el peticionario obtuvo su esquema de seguridad en virtud de su condición de reinsertado en julio de 1997 pero en el escrito de tutela afirmó estar actualmente amenazado debido a su condición de defensor de derechos humanos, la Sala estima que éste deberá, dentro de los cinco (5) días hábiles siguientes a la notificación de esta sentencia, presentar solicitud de protección ante el Programa de Protección de Derechos Humanos del Ministerio del Interior y de Justicia para que sea el Comité de Reglamentación y Evaluación de Riesgos correspondiente, el que determine definitivamente si el peticionario es acreedor de medidas de protección especial debido a estar sometido a una amenaza (ST-339/10, M. P. Juan Carlos Henao Pérez).

\subsection{Sujetos amparados con medidas de protección de la CIDH}

Con la ST-524/05, ${ }^{34}$ la CC en su proceso de revisión de tutelas vuelve a revocar un fallo de instancia expedido por la CSJ, que denegaba el amparo, $\mathrm{y}$, al contrario, lo concede, en razón de estar frente a un sujeto sometido a especial protección constitucional dada su situación de riesgo extraordinario y de estar amparado con medidas cautelares decretadas, en la etapa de solución amistosa, por la Comisión Interamericana de Derechos Humanos (CIDH). Esta entidad requirió: realización de un estudio de seguridad por parte de la Policía Nacional a la vivienda con el objeto de que sea blindada; esquema de seguridad permanente compuesto por mínimo dos miembros de la Policía Nacional; auxilio de mudanza para cambiar de domicilio a otra ciudad que revista mejores condiciones de seguridad; auxilio de transporte para el accionante y sus padres; y la asignación de un acompañante armado previamente escogido por él para su custodia personal.

En este caso, la CC vuelve a recordar el deber de las autoridades administrativas frente a personas sometidas a riesgos extraordinarios:

34 El ciudadano Ricardo Gutiérrez Soler interpuso acción de tutela contra las siguientes entidades: Ministerio del Interior -Grupo de Protección-, Ministerio de Relaciones Exteriores -Dirección de Derechos Humanos y Derecho Internacional Humanitario-, Vicepresidencia de la República -Oficina de Derechos Humanos- y Policía Nacional, pues considera que han vulnerado sus derechos fundamentales a la vida, a la dignidad humana, a la integridad personal, a la libertad y al trabajo, por no haber otorgado las medidas de seguridad que el actor ha solicitado en virtud de ser beneficiario de medidas cautelares decretadas por la Comisión Interamericana de Derechos Humanos. 
Cuando se trata de personas expuestas a riesgos excepcionales, éstas últimas cuentan con el derecho a la seguridad personal, lo cual las faculta para recibir protección adecuada por parte de las autoridades. Además, cuando los niveles de peligro rebasan aquellos implícitos en la vida en sociedad, la obligación del Estado de garantizar la seguridad de los sujetos expuestos a riesgos excepcionales se convierte en una obligación de resultados - para efectos de responsabilidad administrativa-, no ya de medios como la que tiene en relación con la población que no se encuentra en dichas circunstancias especiales [letra cursiva agregada] (ST-524/05, M. P. Humberto Antonio Sierra Porto).

Además, señala la insuficiencia de las medidas adoptadas por el Estado frente a las graves violaciones que recayeron sobre Ricardo Gutiérrez Soler:

Si bien el Estado colombiano ha procurado adelantar y desplegar medidas y actividades tendentes a garantizar la seguridad del ciudadano Ricardo Gutiérrez Soler, minimizando los factores de riesgo a los que él se ha visto expuesto, las mismas [sic] han sido insuficientes para lograr la protección buscada a través del decreto de las medidas cautelares por la CIDH. En efecto, los eventos que dieron lugar al decreto de las mismas [sic], como 'los montajes judiciales', los allanamientos perpetrados sin orden judicial, las detenciones 'irregulares' y los hostigamientos contra él y su familia no han cesado, como lo demuestran los acontecimientos acaecidos con posterioridad al 29 de mayo de 2003 (cuando fueron decretadas medidas cautelares en su favor, por parte de la CIDH), puestos en conocimiento de la Corte por el propio actor y por el Colectivo de Abogados José Alvear Restrepo, peticionarios ante la Comisión Interamericana de Derechos Humanos y que, reitera esta Sala, conllevó el decreto de medidas provisionales en favor de Ricardo Gutiérrez y su familia, por la Corte Interamericana de Derechos Humanos el 11 de marzo del año en curso (ST-524/05, M. P. Humberto Antonio Sierra Porto).

Finalmente, es importante anotar que por este caso Colombia fue condenada por la Corte Interamericana de Derechos Humanos, mediante Sentencia 2005, de 12 de septiembre, que confirmó la violación por parte del Estado de los derechos a la integridad personal, garantías judiciales, protección judicial y libertad personal de la Convención Americana de Derechos. 


\section{Conclusiones}

Los Estados constitucionales actuales están estructurados en el garantismo consagrado en las constituciones, que obligan al protagonismo de los jueces constituciones en torno a la salvaguardada de los derechos, entre los cuales resalta el derecho a la libertad y seguridad personal.

La interpretación del alcance del derecho a la libertad y seguridad personal encuentra en los precedentes desarrollados por la Corte Constitucional colombiana una expansión, comoquiera que esta corporación, en un proceso de interpretación creativa y decisoria, ha ordenado el otorgamiento de protección a exguerrilleros reincorporados a la vida civil, desplazados por la violencia, activistas de derechos humanos, profesores, sindicalistas, abogados y a otros sujetos que ha catalogado como sometidos a protección constitucional especial en razón a las labores que ejercen. Estas órdenes de protección constituyen una garantía secundaria, en el sentido de que la jurisdicción constitucional interviene por la solicitud de los asociados y ante la falta de protección y garantías de las otras ramas, entre las que se incluye de manera específica a la ejecutiva, ya que, derivada de su ineficiente estructura burocrática y de la intervención misma de la fuerza pública, genera un índice importante de las violaciones que desestiman la importancia del derecho a la libertad y seguridad personal, en un Estado como el colombiano, sometido a una guerra irregular que no ha sido superada en 60 años.

La labor de interpretación de la Constitución colombiana por parte de la Corte Constitucional pone en jaque el proceso de interpretación judicial realizado, incluso por parte de los tribunales de cierre de otras jurisdicciones, entre los que se incluye a la Corte Suprema de Justicia de este país, comoquiera que esta continúa interpretando el ordenamiento jurídico bajo un paradigma iuspositivista, con sujeción absoluta a la letra de la ley, desconociendo los postulados del neoconstitucionalismo no solo planteados en la Carta, sino suficientemente desarrollados por la Corte Constitucional. Esta situación se demuestra con el porcentaje de sentencias que la Corte Constitucional revocó en los dos períodos establecidos para la realización de esta investigación, y, por el contrario, otorgó la protección solicitada por los accionantes, antes negada por el máximo tribunal de la jurisdicción ordinaria. 
De acuerdo con los datos de esta investigación, en el período 19922001 se expidieron un total de 446 SC y ST, relativas a las libertades así: el $24 \%$ correspondió a pronunciamientos sobre la libertad personal; un 20\%, a la libertad de configuración legislativa; $\mathrm{y}$, en tercer lugar, encontramos lo relativo a las libertades sindicales y de circulación o locomoción con un $8 \%$.

Lo anterior nos lleva a confirmar que, no obstante la recién expedida Constitución para la Paz, las solicitudes de protección, vía judicial, del derecho a la libertad personal no disminuyeron, presumiblemente ante el afianzamiento del movimiento paramilitar, que en la década de los noventa logró en el país su mayor expansión al unificarse todos los grupos en las Autodefensas Unidas de Colombia (AUC), en abril de 1997; o como continuación de la violencia política, que entonces da cuenta del incremento de actores asociados a la guerra irregular en el país.

Siguiendo ese orden, y bajo la misma lógica de guerra irregular, encontramos que durante la ejecución de la PSD aumentó el número de sentencias expedidas por la CC relativas a las libertades, aunque continuó siendo la libertad personal el derecho sobre el cual recayeron los mayores pronunciamientos.

Del total de 471 sentencias ST y SC que fueron analizadas en su integridad, la libertad personal representó el 29,36\% de los pronunciamientos, es decir, aumentó en un 5,36\% con relación al período anterior, evidentemente mayor, por cuanto representaba nueve años (1992-2001), mientras el que corresponde a la PSD incluye ocho años (2002-2010).

Esto nos plantea como escenario que, en 18 años de jurisdicción constitucional en el país, el mayor número de órdenes de protección se refieren a la libertad personal, con un aumento considerable en el período de PSD. Por consiguiente, la población recurre a la CC ante la ineficacia de la rama ejecutiva para proteger este derecho, e incluso ante la irrupción ilegal de las autoridades del Estado, que, desconociendo su deber constitucional en la materia señalado para todas las personas en su vida, honra y bienes, generan un número importante de estas violaciones, tal y como pudimos constatar de las sentencias contra Colombia por parte de la Corte Interamericana de Derechos Humanos.

Bajo este análisis, se concluye que los precedentes desarrollados por la Corte Constitucional colombiana sirven de guía a los operadores de justicia de este país, comoquiera que se constituyen en parte integrante del texto 
constitucional, además de considerarse vinculantes en el proceso de interpretación. Esta intervención judicial se convierte, de igual manera, en un referente para el constitucionalismo universal, en el sentido de que revela: el marco de actuación del juez constitucional; la labor política que este realiza en la medida en que acude a una interpretación, creativa, decisoria y, sobre todo, adaptada al contexto del país. De esta forma, las decisiones garantistas de esta Corte dan cuenta de que el modelo neoconstitucional, basado en el protagonismo judicial, encuentra en Colombia un nicho de desarrollo, sobre todo frente a tensiones surgidas entre políticas de guerra para superar conflictos que no pueden conllevar al desconocimiento del derecho sobre el cual se ha construido el Estado: la libertad; situación que puede trasladarse a las tensiones que surgen, actualmente, entre las políticas antiterrorismo que desestiman la salvaguarda del derecho a la libertad de los asociados.

Esta investigación supuso el otorgamiento de coherencia interna a los operadores judiciales de Colombia para la aprehensión de los precedentes que deben guiar su actuación en la protección de la libertad y seguridad personal; y en el plano internacional, presenta la forma de actuación de un tribunal garantista, que cumple esta función en un contexto excepcional que requiere ser visibilizado.

\section{Referencias}

Ávila Martínez, A. F. (2008). FARC: dinámica reciente de la guerra. Revista Arcano, (14). Recuperado de http://www.nuevoarcoiris.org.co/sac/files/arcanos/arcanos_14_diciembre_2008_files/arcanos_14_editorial.pdf

Ferrajoli, L. (2008). Democracia y garantismo. Madrid: Trotta.

García Villegas, M., \& Uprimny, R. (2006). ¿Justicia para todos? Bogotá: Norma.

Gaviria, C. (s. f.). Igualdad, libertad y justicia. Cátedra Gerardo Molina, Universidad Libre, Bogotá.

Guatini, R. (2010). Teoría e ideología de la interpretación constitucional.Madrid: Trotta. Molinares, V. (2006). El precedente constitucional: análisis de la Sentencia T-262 de 2006. Revista de Derecho, (35), 143.

Prieto Sanchís, L. (1999). Constitucionalismo y positivismo. México: BEFDP.

Uribe Vargas, D. (1996). Derecho a la paz. Bogotá: Universidad Nacional. 
Uribe, Á. (2009). Perfiles del mal en la historia de Colombia. Bogotá: Universidad Nacional.

\section{Sentencias revisadas}

Colombia, Corte Constitucional. T-062 de 2002, M. P. Clara Inés Vargas Hernández.

Colombia, Corte Constitucional. T-362 de 2002, M. P. Eduardo Montealegre Lynett.

Colombia, Corte Constitucional. T-722 de 2002, M. P. Marco Monroy Cabra.

Colombia, Corte Constitucional. T-785 de 2002, M. P. Clara Inés Vargas Hernández.

Colombia, Corte Constitucional. T-868 de 2002, M. P. Jaime Araújo Rentería.

Colombia, Corte Constitucional. T-894 de 2002, M. P. Álvaro Tafur Galvis.

Colombia, Corte Constitucional. T-895 de 2002, M. P. Álvaro Tafur Galvis.

Colombia, Corte Constitucional. T-839 de 2002, M. P. Álvaro Tafur Galvis.

Colombia, Corte Constitucional. T-223 de 2002, M. P. Clara Inés Vargas Hernández.

Colombia, Corte Constitucional. T-190 de 2002, M. P. Jaime Córdoba Triviño.

Colombia, Corte Constitucional. T-195 de 2002, M. P. Clara Inés Vargas Hernández.

Colombia, Corte Constitucional. T-719 de 2003, M. P. Manuel José Cepeda Espinosa.

Colombia, Corte Constitucional. T-1047 de 2003, M. P. Marco Monroy Cabra.

Colombia, Corte Constitucional. T-1082 de 2003, M. P. Manuel José Cepeda Espinosa.

Colombia, Corte Constitucional. T-338 de 2003, M. P. Marco Monroy Cabra.

Colombia, Corte Constitucional. T-268 de 2003, M. P. Marco Monroy Cabra.

Colombia, Corte Constitucional. T-310 de 2003, M. P. Manuel José Cepeda Espinosa.

Colombia, Corte Constitucional. T-493 de 2003, M. P. Marco Monroy Cabra.

Colombia, Corte Constitucional. T-338 de 2004, M. P. Marco Monroy Cabra.

Colombia, Corte Constitucional. T-455 de 2004, M. P. Jaime Araújo Rentería.

Colombia, Corte Constitucional. T-679 de 2004, M. P. Jaime Córdoba Triviño.

Colombia, Corte Constitucional. T-684 de 2004, M. P. Clara Inés Vargas Hernández.

Colombia, Corte Constitucional. T-596 de 2004, M. P. Manuel José Cepeda Espinosa. 
Colombia, Corte Constitucional. T-899 de 2004, M. P. Jaime Córdoba Triviño. Colombia, Corte Constitucional. T-1239 de 2004, M. P. Rodrigo Escobar Gil. Colombia, Corte Constitucional. T-096 de 2004, M. P. Jaime Araújo Rentería. Colombia, Corte Constitucional. T-1035 de 2004, M. P. Marco Monroy Cabra. Colombia, Corte Constitucional. T-853 de 2004, M. P. Manuel José Cepeda Espinosa.

Colombia, Corte Constitucional. T-804 de 2004, M. P. Álvaro Tafur Galvis. Colombia, Corte Constitucional. T-321 de 2005, M. P. Humberto Sierra Porto. Colombia, Corte Constitucional. T-659 de 2005, M. P. Clara Inés Vargas Hernández.

Colombia, Corte Constitucional. T-1303 de 2005, M. P. Jaime Córdoba Triviño. Colombia, Corte Constitucional. T-524 de 2005, M. P. Humberto Sierra Porto. Colombia, Corte Constitucional. T-634 de 2005, M. P. Manuel José Cepeda Espinosa.

Colombia, Corte Constitucional. T-683 de 2005, M. P. Humberto Sierra Porto. Colombia, Corte Constitucional. T-686 de 2005, M. P. Rodrigo Escobar Gil. Colombia, Corte Constitucional. T-1257 de 2005, M. P. Álvaro Tafur Galvis. Colombia, Corte Constitucional. T-780 de 2005, M. P. Manuel José Cepeda Espinosa.

Colombia, Corte Constitucional. T-676 de 2005, M. P. Humberto Sierra Porto. Colombia, Corte Constitucional. T-694 de 2005, M. P. Jaime Córdoba Triviño. Colombia, Corte Constitucional. T-484 de 2005, M. P. Alfredo Beltrán Sierra. Colombia, Corte Constitucional. T-521 de 2005, M. P. Rodrigo Escobar Gil. Colombia, Corte Constitucional. T-274 de 2005, M. P. Humberto Sierra Porto. Colombia, Corte Constitucional. T-1023 de 2005, M. P. Rodrigo Escobar Gil. Colombia, Corte Constitucional. T-1168 de 2005, M. P. Álvaro Tafur Galvis. Colombia, Corte Constitucional. T-1069 de 2005, M. P. Rodrigo Escobar Gil. Colombia, Corte Constitucional. T-212 de 2006, M. P. Marco Monroy Cabra. Colombia, Corte Constitucional. T-439 de 2006, M. P. Marco Monroy Cabra. Colombia, Corte Constitucional. T-406 de 2006, M. P. Jaime Araújo Rentería. Colombia, Corte Constitucional. T-693 de 2006, M. P. Jaime Araújo Rentería. Colombia, Corte Constitucional. T-723 de 2006, M. P. Nilson Pinilla Pinilla. Colombia, Corte Constitucional. T-724 de 2006, M. P. Álvaro Tafur Galvis. Colombia, Corte Constitucional. T-865 de 2006, M. P. Jaime Araújo Rentería. Colombia, Corte Constitucional. T-1055 de 2006, M. P. Jaime Araújo Rentería. Colombia, Corte Constitucional. T-808 de 2006, M. P. Manuel José Cepeda Espinosa. 
Colombia, Corte Constitucional. T-1037 de 2006, M. P. Humberto Sierra Porto. Colombia, Corte Constitucional. T-1085 de 2006, M. P. Álvaro Tafur Galvis. Colombia, Corte Constitucional. T-133A de 2007, M. P. Rodrigo Escobar Gil. Colombia, Corte Constitucional. T-434 de 2007, M. P. Humberto Sierra Porto. Colombia, Corte Constitucional. T-444 de 2007, M. P. Manuel José Cepeda Espinosa.

Colombia, Corte Constitucional. T-786 de 2007, M. P. Rodrigo Escobar Gil. Colombia, Corte Constitucional. T-226 de 2007, M. P. Clara Inés Vargas Hernández.

Colombia, Corte Constitucional. T-1032 de 2007, M. P. Mauricio González Cuervo. Colombia, Corte Constitucional. T-1032 de 2007, M. P. Mauricio González Cuervo. Colombia, Corte Constitucional. T-715 de 2007, M. P. Nilson Pinilla Pinilla. Colombia, Corte Constitucional. T-824 de 2007, M. P. Jaime Córdoba Triviño. Colombia, Corte Constitucional. T-895 de 2007, M. P. Clara Inés Vargas Hernández.

Colombia, Corte Constitucional. T-496 de 2008, M. P. Jaime Córdoba Triviño. Colombia, Corte Constitucional. T-1101 de 2008, M. P. Humberto Sierra Porto. Colombia, Corte Constitucional. T-1254 de 2008, M. P. Manuel José Cepeda Espinosa.

Colombia, Corte Constitucional. T-393 de 2008, M. P. Clara Inés Vargas Hernández.

Colombia, Corte Constitucional. T-774 de 2008, M. P. Mauricio González Cuervo. Colombia, Corte Constitucional. T-661 de 2008, M. P. Mauricio González Cuervo. Colombia, Corte Constitucional. T-436 de 2008, M. P. Marco Monroy Cabra. Colombia, Corte Constitucional. T-113 de 2009, M. P. Clara Elena Reales Gutiérrez. Colombia, Corte Constitucional. T-578 de 2010, M. P. Luis Vargas Silva.

Colombia, Corte Constitucional. T-339 de 2010, M. P. Juan Carlos Henao Pérez. Colombia, Corte Constitucional. T-728 de 2010, M. P. Luis Vargas Silva. Colombia, Corte Constitucional. T-734 de 2010, M. P. Nilson Pinilla Pinilla. Colombia, Corte Constitucional. T-479 de 2010, M. P. Juan Henao Pérez. Colombia, Corte Constitucional. T-888 de 2010, M. P. María Victoria Calle Correa. Colombia, Corte Constitucional. T-372 de 2010, M. P. Luis Ernesto Vargas Silva. Colombia, Corte Constitucional. T-217 de 2010, M. P. Gabriel Mendoza Martelo. Colombia, Corte Constitucional. C-1024 de 2002, M. P. Alfredo Beltrán Sierra. Colombia, Corte Constitucional. C-316 de 2002, M. P. Marco Monroy Cabra. Colombia, Corte Constitucional. C-371 de 2002, M. P. Rodrigo Escobar Gil. Colombia, Corte Constitucional. C-580 de 2002, M. P. Rodrigo Escobar Gil. 
Colombia, Corte Constitucional. C-805 de 2002, MM. PP. Manuel José Cepeda Espinosa y Eduardo Montealegre Lynett.

Colombia, Corte Constitucional. C-251 de 2002, MM. PP. Eduardo Montealegre Lynett y Clara Inés Vargas Hernández.

Colombia, Corte Constitucional. C-688 de 2002, M. P. Rodrigo Escobar Gil.

Colombia, Corte Constitucional. C-185 de 2002, M. P. Rodrigo Escobar Gil.

Colombia, Corte Constitucional. C-284 de 2002, M. P. Rodrigo Escobar Gil.

Colombia, Corte Constitucional. C-713 de 2002, M. P. Alfredo Beltrán Sierra.

Colombia, Corte Constitucional. C-806 de 2002, M. P. Clara Inés Vargas Hernández.

Colombia, Corte Constitucional. C-416 de 2002, M. P. Clara Inés Vargas Hernández.

Colombia, Corte Constitucional. C-296 de 2002, M. P. Marco Monroy Cabra.

Colombia, Corte Constitucional. C-984 de 2002, M. P. Marco Monroy Cabra.

Colombia, Corte Constitucional. C-478 de 2003, M. P. Clara Inés Vargas Hernández.

Colombia, Corte Constitucional. C-430 de 2003, M. P. Alfredo Beltrán Sierra.

Colombia, Corte Constitucional, Sala Plena. C-530 de 2003.

Colombia, Corte Constitucional. C-622 de 2003, M. P. Álvaro Tafur Galvis.

Colombia, Corte Constitucional. C-039 de 2003, M. P. Manuel José Cepeda Espinosa.

Colombia, Corte Constitucional. C-528 de 2003, M. P. Marco Monroy Cabra.

Colombia, Corte Constitucional. C-030 de 2003, M. P. Álvaro Tafur Galvis.

Colombia, Corte Constitucional. C-184 de 2003, M. P. Manuel José Cepeda Espinosa.

Colombia, Corte Constitucional. C-123 de 2004, M. P. Marco Monroy Cabra.

Colombia, Corte Constitucional. C-863 de 2004, M. P. Manuel José Cepeda Espinosa.

Colombia, Corte Constitucional. C-1054 de 2004, M. P. Clara Inés Vargas Hernández.

Colombia, Corte Constitucional. C-101 de 2005, M. P. Alfredo Beltrán Sierra.

Colombia, Corte Constitucional. C-237 de 2005, M. P. Jaime Araújo Rentería.

Colombia, Corte Constitucional. C-730 de 2005, M. P. Álvaro Tafur Galvis.

Colombia, Corte Constitucional. C-1001 de 2005, M. P. Álvaro Tafur Galvis.

Colombia, Corte Constitucional. C-850 de 2005, M. P. Jaime Araújo Rentería.

Colombia, Corte Constitucional. C-1260 de 2005, M. P. Clara Inés Vargas Hernández. 
Colombia, Corte Constitucional. C-194 de 2005, M. P. Marco Monroy Cabra. Colombia, Corte Constitucional. C-239 de 2005, M. P. Humberto Sierra Porto. Colombia, Corte Constitucional. C-665 de 2005, M. P. Rodrigo Escobar Gil. Colombia, Corte Constitucional. C-187 de 2006, M. P. Clara Inés Vargas Hernández.

Colombia, Corte Constitucional. C-400 de 2006, M. P. Alfredo Beltrán Sierra. Colombia, Corte Constitucional. C-176 de 2007, M. P. Marco Monroy Cabra. Colombia, Corte Constitucional. C-479 de 2007, M. P. Álvaro Tafur Galvis.

Colombia, Corte Constitucional. C-291 de 2007, M. P. Manuel José Cepeda Espinosa.

Colombia, Corte Constitucional. C-720 de 2007, M. P. Catalina Botero Marino.

Colombia, Corte Constitucional. C-189 de 2008, M. P. Manuel José Cepeda Espinosa.

Colombia, Corte Constitucional. C-226 de 2008, M. P. Humberto Sierra Porto. Colombia, Corte Constitucional. C-318 de 2008, M. P. Jaime Córdoba Triviño. Colombia, Corte Constitucional. C-425 de 2008, M. P. Marco Monroy Cabra. Colombia, Corte Constitucional. C-1198 de 2008, M. P. Nilson Pinilla Pinilla.

\section{Sentencias presentadas en el artículo}

Colombia, Corte Constitucional. T-719 de 2003, M. P. Manuel José Cepeda Espinosa.

Colombia, Corte Constitucional. T-268 de 2003, M. P. Marco Monroy Cabra.

Colombia, Corte Constitucional. T-377 de 2003, M. P. Jaime Córdoba Triviño. Colombia, Corte Constitucional. T-327 de 2004, M. P. Alfredo Beltrán Sierra. Colombia, Corte Constitucional. T-804 de 2004, M. P. Álvaro Tafur Galvis. Colombia, Corte Constitucional. T-524 de 2005, M. P. Humberto Sierra Porto. Colombia, Corte Constitucional. T-683 de 2005, M. P. Humberto Sierra Porto. Colombia, Corte Constitucional. T-686 de 2005, M. P. Rodrigo Escobar Gil. Colombia, Corte Constitucional. T-895 de 2007, M. P. Clara Inés Vargas Hernández.

Colombia, Corte Constitucional. T-1101 de 2008, M. P. Humberto Sierra Porto. Colombia, Corte Constitucional. T-496 de 2008, M. P. Jaime Córdoba Triviño. Colombia, Corte Constitucional. T-1254 de 2008, M. P. Manuel José Cepeda Espinosa.

Colombia, Corte Constitucional. T-1037 de 2008, M. P. Jaime Córdoba Triviño. Colombia, Corte Constitucional. T-134 de 2010, M. P. Nilson Pinilla Pinilla. 
Colombia, Corte Constitucional. T-728 de 2010, M. P. Luis Vargas Silva.

Colombia, Corte Constitucional. T-339 de 2010, M. P. Juan Carlos Henao Pérez.

Colombia, Corte Constitucional. T-372 de 2010, M. P. Luis Vargas Silva. 